\title{
COORDINATING A DECENTRALIZED SUPPLY CHAIN WITH CAPACITY COST COMPENSATION
}

\author{
Feifei Shan ${ }^{1}$, Xiaopei Dai ${ }^{2}$, Jinqi Men ${ }^{1}$ And Feng Yang ${ }^{1, *}$
}

\begin{abstract}
Capacity planning, as a vital asset, is a challenge problem for firms in various industries, such as organic agriculture, apparels and high-tech industry. However, many manufacturers are conservative about their capacity investment for a variety of reasons. As a result, many retailers have the motivation to stimulate manufacturers to enhance the capacity level. In this paper, we propose a revenue sharing and capacity cost compensation contract to help the retailer stimulate her manufacturer to increase the capacity level. In the contract, the retailer keeps a portion of sales revenue and compensates for the manufacturer's capacity cost. They face a stochastic demand and play a Stackelberg game where the retailer acts as a leader and the manufacturer acts as a follower. We prove that the channel can be perfectly coordinated through our proposed contract. Moreover, we give a feasible range of profit distribution, in which both channel members can earn no less profit than that in noncooperation. Meanwhile, comparing with centralized channel with multiplicative demand, we find that capacity in decentralized channel tends to be lower.
\end{abstract}

Mathematics Subject Classification. 90Bxx, 91Axx.

Received October 14, 2019. Accepted May 19, 2020.

\section{INTRODUCTION}

Capacity investment, as an important competitive tool, is a challenge faced by firms in many industries such as high-tech industry, organic agriculture, fashion goods and apparels. For example, in the past years, the global component with electronics is shortage and the shortage is expected to last until 2018 [19]. Due to rapid development of consumer electronic industry, especially for the smartphone market, the demand for semiconductors is booming in recent years. However, its production capacity has not kept pace with the increase in demand. One reason is that the semiconductor is a high-tech industry and it needs a lot of Research and Development investments in the early stage, which keeps most firms out. The other reason is technology breakthrough occurs frequently and thus there is limited historical data to precisely predict the market demand of a new product [12]. The demand uncertainty is high in high-tech and innovative industries [6]. Furthermore, the semiconductor supplier is concerned that demand is growing too fast and it will cause overcapacity once demand shrinks

Keywords. Supply chain management, capacity compensation, cooperative game, coordination mechanism.

1 School of Management, University of Science and Technology of China, \#96 JinZhai Road, Baohe District, Hefei, Anhui 230026, P.R. China.

2 Hunan Key Laboratory of Macroeconomic Big Data Mining and its Application, School of Business, Hunan Normal University, Changsha, Hunan 410081, P.R. China.

*Corresponding author: fengyang@ustc.edu.cn 
[19]. Therefore, the entry barriers coupled with demand uncertainty creates the shortage. To reduce the risk of capacity investment, sometimes a manufacturer tends to provide relatively low capacity. For instance, the iPhone produced by Apple Inc. is updated once a year, which needs frequent upgrades and replacement of production line. And in view of this, Foxconn, as the production agent of Apple's mobile, is very cautious in improving production or service capacity, which often leads to supply shortage after each replacement.

With the development of the society, consumers' demand for organic products are increasing. In the apparel industry, consumers are willing to pay more for the organic cotton and they expect products to be more environmental friendly. That is the motivation for the manufacturers in apparel industry like H\&M to source from organic supplier. According to H\&M, the share of organic cotton rose from $7.8 \%$ in 2012 to $10.8 \%$ in 2013 [14]. However, it is hard for farmers to grow organic cotton. One reason is the lack of effective training, and $\mathrm{H} \& \mathrm{M}$ also finds it is a tough task to train farmers to produce organic cotton [14]. The other reason is that the organic cotton seed is difficult to access ${ }^{1}$.

As the examples illustrated above, the upstream suppliers may not be able to provide sufficient production capacity for various reasons. As a result, downstream buyers have the motivation to take some effective measures to stimulate upstream suppliers to offer a higher capacity. Erkoc and $\mathrm{Wu}$ [9] show that a buyer can incentivize its supplier to expand capacity more aggressively by paying a deductible fee in the high-tech industry. In the organic agriculture industry, the downstream buyer also takes measures to help its suppliers to grow organic cotton. For example, in order to strengthen the cotton producers' self-confidence to grow organic cotton, the German brand Cotonea provides them with financial security and supports them in capacity building ${ }^{2}$.

We attempt to find a win-win contract for both the buyer and its supplier, and also enable the channel to create additional surpluses. Previous literatures also try to propose a proper contract to coordinate the decentralized supply chain. Among those, the revenue sharing contract is widely used in supply chain coordination $[2,5]$. In the contract, a retailer shares sales revenue with a manufacturer. In order to stimulate the manufacturer's desire for production, some retailers introduce production cost sharing in revenue sharing contract $[7,25]$. In our paper, we propose a revenue sharing and capacity cost sharing mechanism to help a downstream buyer incentive its supplier to build more capacity. In this contract, a retailer shares a fraction of capacity cost.

The following channel settings support us to perform our investigation. We introduce a supply chain with an upstream manufacturer (referred to as "he") and a downstream retailer (referred to as "she"). The manufacturer sells his product through a single retailer in the market. Capacity building needs a long lead time that the manufacturer should invest capacity far in advance of sales season [11,22]. At this point, the demand information is not revealed and thus the manufacturer's capacity investment depends on the retailer's forecast of demand. It was not until the sales season that the manufacturer made production and the demand uncertainty is resolved at this point.

In a decentralized channel, both supply chain partners make decisions based on their own profits, which often results in a loss of the whole channel profit. Maximizing the overall channel profit requires the execution of a precise set of actions. In such a circumstance, we propose a cooperative mechanism to coordinate the partner of the channel to achieve the optimal channel profit. The purpose of this paper is to find a feasible mechanism to coordinate the supply chain members to achieve optimal supply chain profit and lessen the bad effect of uncertain demand on capacity building. This article mainly addresses the following key questions:

(1) Does the contract we proposed stimulate the manufacturer to provide a higher capacity?

(2) Can the decentralized supply chain be coordinated under our proposed contract?

(3) If the decentralized supply chain can be coordinated, how is the supply chain profit allocated between the channel members?

\footnotetext{
1 New Report Confirms Challenges of Sourcing Seed For Organic Cotton Cultivation (http://www.greencotton.org/ wp-content/uploads/Press-release-Seed-Report-May-2015.pdf)

2 Organic Cotton Market Report 2016 (http://textileexchange.org/wp-content/uploads/2017/02/TE-Organic-CottonMarket-Report-0ct2016.pdf)
} 
We introduce Stackelberg game to model the decision making of the two firms. In Stackelberg game, the downstream retailer, acting as a leader, offers the manufacturer a take-it-or-leave-it contract in advance of a sales season. The contract specifies the fraction of the capacity cost and sales revenue. The upstream manufacturer, acting as a follower, decides the capacity level, retail price upon seeing the capacity cost sharing contract provided by the retailer. The manufacturer will accept the contract if it can bring a positive expected profit for him.

Our analysis leads to some significant conclusions. First, we prove that the optimal capacity in centralized channel is higher than that in the decentralized channel under multiplicative stochastic demand. Second, the revenue sharing contract cannot coordinate the supply chain, while the decentralized supply chain can achieve coordination perfectly with the revenue sharing and capacity cost compensation contract. The research also gives a feasible range of profit distribution, in which both the manufacturer and the retailer acquire no less profit than that in non-cooperation. Then members can bargain over the revenue sharing and the proportion of the capacity cost depending on their bargaining power.

The remainder of the paper is organized as follows: in Section 2, we review the relevant literature. Model notations and centralized channel are presented in Section 3. In Section 4, we discuss the mechanism with revenue sharing. In Section 5, we analyze the contract with capacity cost compensation. And we give multiplicative demand analysis and numerical study in Section 6. Finally, we summarize our findings in Section 7.

\section{LiteratuRE REVIEW}

The model setting considered in this paper has two distinctive features: (1) supply chain coordination contract, (2) capacity management. We discuss each in the following section.

In this paper, we set up a contract to coordinate a supply chain with capacity investment. Contract is an effective tool to allocate the channel profit $[15,26]$. Many researchers tried to build some mechanisms to improve overall chain performance under the condition that allowing channel members to achieve their individual objectives $[1,23]$. One stream of this area is to introduce a contract to coordinate the channel members' behavior to benefit both sides of the channel Jin et al. [13] analyze the effective of wholesale price contract and consignment the contract with revenue sharing in supply chain management with a capital constrained retailer.

Plenty of researchers have tried to find how to manage capacity investment. Some of them turn to the study of capacity investment strategy [4,22]. Swinney et al. [22] analyze the impacts of capacity investment timing (early investment versus late investment) between a start-up firm and an established firm with different degrees of demand uncertainty over time. They show the equilibrium solutions of the capacity investment timing game. Chod and Zhou [4] study the optimal capacity technology choice (flexible versus nonflexible) under financial leverage. Another stream of the related literature tries to find a way to utilize the capacity more effectively $[3,27,28]$. Xie et al. [28] examine the capacity allocation policies between the service provider and the direct selling market. They find the channel performance is improved when introducing the direct selling market. $\mathrm{Wu}$ and Chao [28] consider a stochastic production system with limited production capacity under stochastic demand. They show insights on the structure of the optimal control policies.

Numerous studies try to solve the capacity investment problems through using supply chain contracts or mechanism $[8,10,20]$. Plambeck and Taylor $[20]$ show the influences of renegotiation on capacity investment and innovation, members' resulting profits and so on. They demonstrate that if the contracts are designed correctly, renegotiation can greatly enhance the firms' investments and profits. Oh and Özer [17] study the forecast demand information sharing under uncertainty and dynamic environment. The supplier makes his capacity investment decision according to the demand information he obtained. They promote a Martingale Model of Asymmetric Forecast Evolutions framework to model the firms' forecasting processes. They introduce a mechanism that tries to realize reliable forecast information sharing. And they prove that, through the use of the contract, capacity investment decisions can almost coordinate the supply chain. Roels and Tang [21] try to find a winwin mechanism between two bidirectional alliances firms. In the alliances, one firm shares its manufacturing capacity with another while the other firm shares its distribution capacity. Roels and Tang [21] propose two 


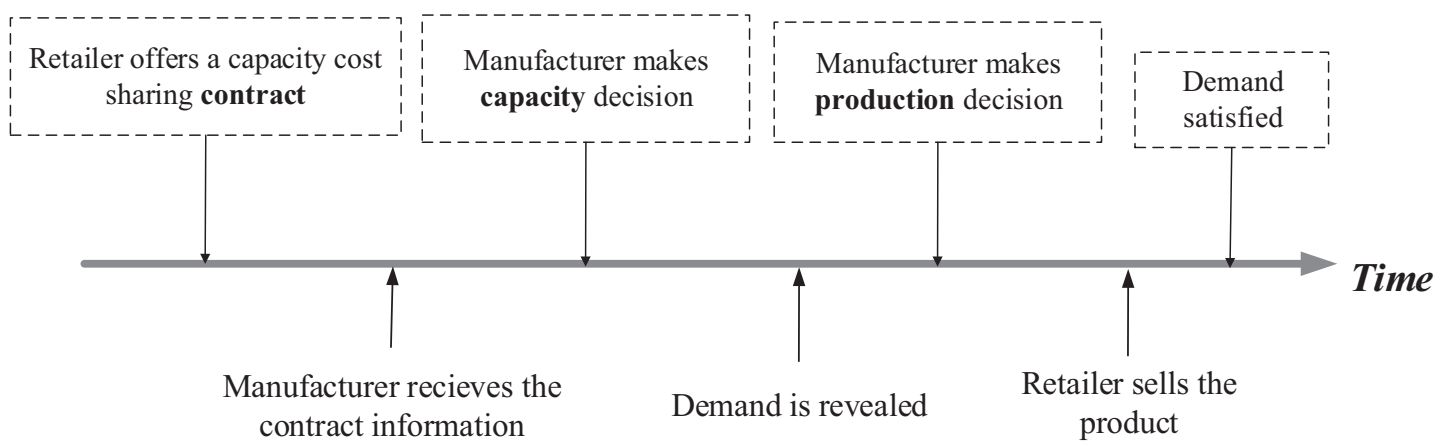

FiguRE 1. Sequence of events.

types of bidirectional contracts (ex-post transfer payment contract and ex-ante capacity reservation contract) to coordinate the alliances. They show that, through using the contracts, the alliance's total profit is improved in equilibrium.

In this paper, we set up a capacity cost sharing contract, in which a retailer shares the capacity cost with her manufacturer, to encourage manufacturer to invest more on capacity building. We prove that the decentralized supply chain can be coordinated under our proposed contract.

\section{Model Description AND CENTRALizED CHANNEL}

Before studying the effect of capacity cost sharing contract on coordinating the supply chain, we first give the model descriptions, notations and assumptions.

\subsection{Model description}

We consider a supply chain consisting of a retailer and a manufacturer who expect to maximize their expected profits. The consumer demand is stochastic and price-sensitive. In order to stimulate the manufacturer to offer a higher capacity level, the retailer offers a contract, which specifies the fraction of capacity cost she would like to share. Upon seeing the contract, the manufacturer makes decision on capacity investment.

The manufacturer's production capacity, $K$, has to be established far in advance of the sales season considering the lead time of capacity building. At this time, there is little information about the consumer demand and the demand uncertainty is not resolved. As time passes, more information about consumer demand is revealed and the demand uncertainty is resolved. The manufacturer makes production decision after observing the demand information. The product quantity that the manufacturer decides to release to the market is $q$ and it obeys to the constraint i.e., $q \leq K$. The manufacturer does not produce up to his capacity. When the actual demand exceeds the manufacturer's capacity i.e., $D(p, \xi) \geq K$, he will produce up to his capacity i.e., $q=K$. While, when the actual demand is less than the manufacturer's capacity i.e., $D(p, \xi)<K$, he will produces up to the demand, $q=D(p, \xi)$. The sequence of events is shown in Figure 1. Notations are summarized in Table 1.

We add superscript "** to the relative variables to represent their corresponding optimal values. And subscript " $c$ ", " $d$ ", " $s "$ respectively represent the relative variables in centralized channel, decentralized channel and decentralized channel with capacity cost sharing.

\subsection{Centralized channel}

To analyze the effect of capacity cost sharing contract on coordinating the supply chain, we begin by introducing the centralized channel. 
TABLE 1. Notation.

\begin{tabular}{ll}
\hline \hline Symbol & Definition \\
\hline$p$ & The product's retail price \\
$D(p, \xi)$ & Price-dependent demand and $\xi$ is random variable \\
$F(\cdot)$ & Cumulative distribution function of demand \\
$f(\cdot)$ & Probability density function of demand \\
$c_{m}$ & The manufacturer's marginal production cost \\
$c_{r}$ & The retailer's marginal sales cost \\
$g_{m}$ & The manufacturer's per unit loss because of short supply \\
$g_{r}$ & The retailer's per unit loss because of short supply \\
$\emptyset$ & The retailer's shared revenue for each unit of product sold \\
$\pi$ & The expected profit function \\
$\pi^{r}$ & The retailer's expected profit function in revenue sharing contract \\
\hline Decision & Definition \\
variable & \\
\hline$q$ & The manufacturer's production quantity \\
$K$ & The manufacturer's production capacity \\
$\theta$ & The fraction of capacity cost that the retailer shared with the manufacturer \\
\hline
\end{tabular}

Now, we introduce our demand function. Prior to the sales season, the demand information is not revealed and we assume the demand is stochastic and price-sensitive denoted by $D(p, \xi)$. In the demand function, $\xi$ is a random variable supported on $\left[\delta_{1}, \delta_{2}\right]$ and $0 \leq \delta_{1} \leq \delta_{2}[16,25]$. The expected order quantity of the downstream retailer is

$$
\begin{aligned}
q(K, p) & =E \min \{D(p, \xi), K\} \\
& =K[1-F(K \mid p)]+\int_{0}^{K} y f(y \mid p) \mathrm{d} y \\
& =K-\int_{0}^{K} F(y \mid p) \mathrm{d} y
\end{aligned}
$$

where $\min \{D(p, \xi), K\}$ is the retailer's order quantity (notice that the retailer decides the order quantity based on actual demand) and $F(K \mid p)$ is the distribution function of consumer demand and strictly increases in $K$. Meanwhile $F(\cdot)$ is differentiable on $\left[\delta_{1}, \delta_{2}\right]$. We assume the demand function decreases stochastically in price, i.e., $\frac{\partial F(K \mid p)}{\partial p}<0$. This assumption is widely used in coordination research [1].

When the manufacturer's optimal capacity is insufficient to meet the demand, some consumers will not be able to obtain products and short supply will happen. The manufacturer and the retailer have an opportunity loss, respectively denoted by $g_{m}$ and $g_{r}$, caused by the short supply. The excepted lost sales of the supply chain is,

$$
\begin{aligned}
L(K, p) & =E[D(p, \xi)-K]^{+} \\
& =\int_{K}^{\infty}(y-K) f(y \mid p) \mathrm{d} y+\int_{0}^{K} y f(y \mid p) \mathrm{d} y-\int_{0}^{K} y f(y \mid p) \mathrm{d} y \\
& =\int_{K}^{\infty} y f(y \mid p) \mathrm{d} y+\int_{0}^{K} y f(y \mid p) \mathrm{d} y-K \int_{K}^{\infty} f(y \mid p) \mathrm{d} y-\int_{0}^{K} y f(y \mid p) \mathrm{d} y
\end{aligned}
$$




$$
\begin{aligned}
& =\int_{0}^{\infty} y f(y \mid p) \mathrm{d} y-K[1-F(K \mid p)]-\int_{0}^{K} y f(y \mid p) \mathrm{d} y \\
& =\int_{0}^{\infty} y f(y \mid p) \mathrm{d} y-\left(K-\int_{0}^{K} F(y \mid p) \mathrm{d} y\right) \\
& =h-q(K, p),
\end{aligned}
$$

where $h=\int_{0}^{\infty} y f(y \mid p) \mathrm{d} y$.

In the decentralized supply chain, the manufacturer and the retailer make interactive actions only to benefit themselves. If channel members make decisions based on their own profits, the supply chain cannot achieve maximum profits in most cases. On the contrary, in the centralized supply chain, the system makes decisions from the perspective of the entire channel profit, which maximizes supply chain profit. In the centralized game, the expected profit function is

$$
\begin{aligned}
\pi_{c} & =\left(p-c_{m}-c_{r}\right) q(K, p)-\left(g_{m}+g_{r}\right) L(K, p)-c K \\
& =\left(p-c_{m}-c_{r}+g_{m}+g_{r}\right) q(K, p)-\left(g_{m}+g_{r}\right) h-c K .
\end{aligned}
$$

Equation (3.1) needs not be concave nor unimodal [18]. The expected profit of the centralized game has a maximum value on capacity level $(K)$. The first-order condition of the whole system on capacity level $K$ is

$$
\frac{\partial \pi_{c}}{\partial K}=\left(p-c_{m}-c_{r}+g_{m}+g_{r}\right)[1-F(K \mid p)]-c .
$$

And the first-order condition of the whole channel on retailer price $(p)$

$$
\frac{\partial \pi_{c}}{\partial p}=q\left(K_{c}^{*}, p\right)+\left(p-c_{m}-c_{r}+g_{m}+g_{r}\right) \frac{\partial q\left(K_{c}^{*}, p\right)}{\partial p} .
$$

Letting equation (3.2) equals to zero, we can acquire the best respond of capacity. The optimal capacity is

$$
K_{c}^{*}=F^{-1}\left(\frac{p-c_{m}-c_{r}+g_{m}+g_{r}-c}{p-c_{m}-c_{r}+g_{m}+g_{r}} \mid p\right)
$$

Similarly, letting equation (3.3) equals to zero, we obtain the optimal retailer price. However, it is hard to acquire the explicit expression of the optimal retailer price. We show the implicit expression of the optimal retailer price $\left(p_{c}^{*}\right)$ :

$$
\frac{\partial \pi_{c}}{\partial p}=q(K, p)+\left(p-c_{m}-c_{r}+g_{m}+g_{r}\right) \frac{\partial q(K, p)}{\partial p}=0
$$

This first-order condition is necessary for coordination.

\section{Decentralized With ReVEnUe SHARing}

Then we will consider a supply chain that consists of a single manufacturer, who selling her products through a single retailer with stochastic demand. And in this section, we discuss that the manufacturer and the retailer try to increase their respective profit through a revenue sharing contract. The retailer offers a revenue sharing contract, which identifying the percentage of revenue that she is willing to pay to the manufacturer. Then the manufacturer decides his capacity level. After observing the contract, the manufacturer decides his capacity level and retail price. All of the above decisions are made before the selling season for a long lead time of capacity building. Demand information has not been revealed yet and they can only make decisions depending 
on the demand forecast. After the selling season comes, the retailer decides her order quantity according to actual demand.

Each channel member makes decisions based on their own profits and they play a Stackelberg game. In the game, the retailer, acting as a leader specifies sales revenue's percentage allocation. The manufacturer, acting as a follower, chooses his capacity level and retail price. The manufacturer's expected profit is given by

$$
\begin{aligned}
\pi_{d}^{m} & =\left[\left(1-\emptyset_{d}\right) p-c_{m}\right] q(K, p)-g_{m} L(K, p)-c K \\
& =\left[\left(1-\emptyset_{d}\right) p-c_{m}+g_{m}\right] q(K, p)-g_{m} h-c K .
\end{aligned}
$$

The manufacturer first decides his capacity level. The first-order condition of the manufacturer's expected profit on capacity level is:

$$
\frac{\partial \pi_{d}^{m}}{\partial K}=\left[\left(1-\emptyset_{d}\right) p-c_{m}+g_{m}\right][1-F(K \mid p)]-c .
$$

And the first-order condition of the manufacturer on parameter $p_{d}^{*}$ is

$$
\frac{\partial \pi_{d}^{m}}{\partial p}=q(K, p)+\left[\left(1-\emptyset_{d}\right) p-c_{m}+g_{m}\right] \frac{\partial q(K, p)}{\partial p} .
$$

Letting equation (4.2) equals to zero and solving it, we can acquire the optimal capacity level of the manufacturer. The best response of the capacity level in the decentralized supply chain is

$$
K_{d}^{*}=F^{-1}\left(\frac{\left(1-\emptyset_{d}\right) p-c_{m}+g_{m}-c}{\left(1-\emptyset_{d}\right) p-c_{m}+g_{m}} \mid p\right) .
$$

Letting equation (4.3) equals to zero, the optimal retailer price $\left(p_{d}^{*}\right)$ is determined by the following equation:

$$
\frac{\partial \pi_{d}^{m}}{\partial p}=q(K p)+\left[\left(1-\emptyset_{d}\right) p-c_{m}+g_{m}\right] \frac{\partial q(K, p)}{\partial p}=0 .
$$

A supply chain achieves coordination when the optimal decisions in the decentralized supply chain are the same with that in the centralized supply chain. If a revenue sharing contract can coordinate this supply chain, the optimal capacity level and retailer price in decentralized channel (respectively $K_{d}^{*}, p_{d}^{*}$ ) have to be equal to that in centralized channel $\left(K_{c}^{*}, p_{c}^{*}\right)$, i.e., $K_{d}^{*}=K_{c}^{*}$ and $p_{d}^{*}=p_{c}^{*}$. Comparing equation (4.4) with (3.4) and equation (4.5) with (3.5), we find that only when the revenue sharing $\emptyset_{d}$ satisfies the condition $\emptyset_{d}=\left(c_{r}-g_{r}\right) / p$, can the equations $K_{d}^{*}=K_{c}^{*}$ and $p_{d}^{*}=p_{c}^{*}$ are always true. It means that the retailer's optimal revenue sharing $\left(\emptyset_{d}^{*}\right)$ has to satisfy $\emptyset_{d}^{*}=\emptyset_{d}=\left(c_{r}-g_{r}\right) / p$. However, the retailer will choose this revenue sharing only when it could bring no less benefit than the optimal revenue sharing in the decentralized channel. In fact, the optimal revenue sharing in the decentralized channel $\left(\emptyset_{d}^{*}\right)$ can bring no less profit than the revenue sharing $\emptyset_{d}=\left(c_{r}-g_{r}\right) / p$, considering that the $\emptyset_{d}^{*}$ is determined by maximizing the retailer's expected profit.

In the numerical study (see Sect. 7), we find that revenue sharing condition cannot ensure both members gain more profit than that in decentralized channel. Therefore, we need to seek new ways to coordinate the supply chain.

\section{DeCEntralized With CAPACITy COMPENSATION AND REVEnUE SHARING}

As we have discussed before, the manufacturer may provide a lower capacity level to prevent sluggish demand. In order to stimulate manufacturer to provide a higher capacity level and then increase channel profit, the retailer offers the manufacturer a revenue sharing with a capacity compensation contract. In the contract, the retailer shares a portion of revenue with the manufacturer and also pays a certain compensation for per unit capacity the manufacturer built. In this section, we examine the coordination effect of the contract in the decentralized 
channel. The channel members also play a Stackelberg game. The retailer acts as a leader and the manufacturer acts as a follower. The expected profit of the manufacturer is given by

$$
\begin{aligned}
\pi_{s}^{m} & =\left[(1-\emptyset) p-c_{m}\right] q(K, p)-g_{m} L(K, p)-(1-\theta) c K \\
& =\left[(1-\emptyset) p-c_{m}+g_{m}\right] q(K, p)-g_{m} h-(1-\theta) c K
\end{aligned}
$$

where $\theta$ is the portion of the capacity cost shared by the retailer and $1-\theta$ is the portion of the capacity cost shared by the manufacturer. The first-order condition for the manufacturer's expected profit on capacity level in a revenue sharing with capacity compensation contract is:

$$
\frac{\partial \pi_{s}^{m}}{\partial K}=\left[(1-\emptyset) p-c_{m}+g_{m}\right][1-F(K \mid p)]-(1-\theta) c .
$$

Letting equation (5.2) equals to zero, we can easily find that the supplier's best response of capacity level is

$$
K_{s}^{*}=F^{-1}\left(\frac{\left(1-\emptyset_{s}\right) p-c_{m}+g_{m}-(1-\theta) c}{\left(1-\emptyset_{s}\right) p-c_{m}+g_{m}} \mid p\right)
$$

Similarly, letting the first-order condition of the manufacturer's expected profit on retailer price equals to zero, we can acquire the implicit expression of the optimal retailer price $\left(p_{s}^{*}\right)$

$$
\frac{\partial \pi_{s}^{m}}{\partial p}=q(K, p)+\left[\left(1-\emptyset_{s}\right) p-c_{m}+g_{m}\right] \frac{\partial q(K, p)}{\partial p}=0 .
$$

If a revenue sharing with capacity compensation contract can coordinate this supply chain, the optimal capacity level and retailer price in this decentralized channel (respectively $K_{s}^{*}, p_{s}^{*}$ ) have to be equal to that in centralized channel $\left(K_{c}^{*}, p_{c}^{*}\right)$, i.e., $K_{d}^{*}=K_{s}^{*}$ and $p_{s}^{*}=p_{c}^{*}$. Comparing equation (5.3) with (3.4) and equation (5.4) with (3.5), we find that, when the revenue sharing $\emptyset_{s}$ satisfies the condition

$$
\emptyset_{s}=1-\lambda-\frac{c_{m}-g_{m}-\lambda\left(c_{m}+c_{r}-g_{m}-g_{r}\right)}{p}
$$

and capacity cost compensation $\theta$ satisfies the condition

$$
\theta=1-\lambda,
$$

the equations $K_{s}^{*}=K_{c}^{*}$ and $p_{s}^{*}=p_{c}^{*}$ always hold, where $\lambda$ can be any non-zero value $(\lambda \neq 0)$.

Substituting equations (5.5) and (5.6) into (5.1), we find

$$
\pi_{s}^{m}=\lambda \pi_{c}+h\left[\lambda\left(g_{m}+g_{r}\right)-g_{m}\right] .
$$

Meanwhile, it is easy to get

$$
\pi_{s}^{r}=(1-\lambda) \pi_{c}-h\left[\lambda\left(g_{m}+g_{r}\right)-g_{m}\right] .
$$

Notice that parameters $h=\int_{0}^{\infty} y f(y \mid p) \mathrm{d} y, g_{m}$ and $g_{r}$ are independent of decision variables retailer price $(p)$, capacity level $(K)$, revenue sharing $(\emptyset)$ and capacity cost compensation $(\theta)$. As a results, the equations (5.7) and (5.8) indicate that the optimal decisions of both the manufacturer and the retailer are consistent with the whole system. Therefore, under the conditions of equations (5.5) and (5.6), the decentralized channel in a revenue sharing with a capacity compensation contract can achieve coordination. We have the following proposition:

Proposition 5.1. In a decentralized supply chain with a stochastic demand, a revenue sharing with a capacity cost compensation contract can coordinate the supply chain under the conditions $\emptyset_{s}=1-\lambda-$ $\frac{c_{m}-g_{m}-\lambda\left(c_{m}+c_{r}-g_{m}-g_{r}\right)}{p}$ and $\theta=1-\lambda$ where

$$
0 \leq \lambda \leq 1 \quad \text { and } \quad\left\{\begin{array}{l}
\lambda \pi_{c}+h\left[\lambda\left(g_{m}+g_{r}\right)-g_{m}\right] \geq \pi_{d}^{m *} \\
(1-\lambda) \pi_{c}-h\left[\lambda\left(g_{m}+g_{r}\right)-g_{m}\right] \geq \pi_{d}^{r *}
\end{array}\right.
$$


The above proposition shows that, using the contract we proposed, we can coordinate the whole supply chain. And both the manufacturer and the retailer can obtain a satisfactory profit (no less than that in the decentralized supply chain, see Sect. 4) by adjusting the parameter $\lambda . \lambda \pi_{c}+h\left[\lambda\left(g_{m}+g_{r}\right)-g_{m}\right] \geq \pi_{d}^{m *}$ and $(1-\lambda) \pi_{c}-h\left[\lambda\left(g_{m}+g_{r}\right)-g_{m}\right] \geq \pi_{d}^{r *}$ are the effective allocation conditions of the profit. These conditions ensure that each channel member acquires no less profit in the cooperative context than that in the uncooperative context. Equations (5.7) and (5.8) indicate that the system can adjust the allocation of profit by adjusting the parameter $\lambda$.

This proposition indicates that the decentralized channel can be coordinated by our proposed revenue sharing and capacity cost compensation contract. And the retailer can adjust the channel profit allocation by choosing a proper value of $\lambda$. Proposition 5.1 suggests that a downstream retailer had better to offer a revenue sharing and capacity cost compensation contract to the upstream manufacturer and both channel members can benefit from the contract.

In our contract, the retailer gives compensation for capacity cost based on the manufacturer's capacity level. The main purpose of this measure is to stimulate the upstream manufacturer to provide a higher capacity level and reduce the possibility of short supply. Next, we examine whether the revenue sharing and capacity cost compensation contract can improve the manufacturer's capacity level. Notice that $F(\cdot)$ is strictly increasing, and then $F(\cdot)$ is strictly increasing, too. Comparing the equation (5.3) with (4.4), we can acquire the condition where the manufacturer provide a higher capacity level in the decentralized channel with revenue sharing and capacity cost compensation.

Proposition 5.2. The manufacturer will provide a higher capacity level in a decentralized supply chain with revenue sharing and capacity cost compensation contract when his shared portion of revenue $\left(1-\emptyset_{s}\right)$ satisfies $1-\emptyset_{s} \geq \frac{\theta\left(c_{m}-g_{m}\right)+(1-\theta)\left(1-\emptyset_{d}^{*}\right) p_{d}^{*}}{p_{s}^{*}}$. Otherwise, he will provide a lower capacity level.

It is easy to find that $\frac{\theta\left(c_{m}-g_{m}\right)+(1-\theta)\left(1-\emptyset_{d}^{*}\right) p_{d}^{*}}{p_{s}^{*}}$ increases in the retailer's capacity cost compensation $(\theta)$, which indicates that the retailer can stimulate his manufacturer to offer a higher capacity through raising the manufacturer's revenue sharing or increasing the capacity cost compensation.

\section{Multiplicative Demand AnAlysis}

There exist two classical forms of demand function $D(p, \xi)$ : a multiplicative functional demand $D(p, \xi)=y(p) \xi$ and an additive demand function $D(p, \xi)=y(p)+\xi . y(p)$ denotes a price-sensitive demand and takes the form of $y(p)=a p(a>0 \cdot b>1)$ in the multiplicative case. And in the additive demand function, $y(p)$ takes the form of $y(p)=a-b p(a>0 \cdot b>1)$. In this section, we discuss the effect of the multiplicative demand. In the multiplicative formulation, the parameter $b$ is the price-elasticity index of demand. The larger the value of $b$, the more sensitive the demand for price changes. If the price-elasticity index of demand is greater than 1 , a product is defined as price elastic. On the contrary, if the price-elasticity index is no more than 1 , a product is defined as price inelastic. We focus on price-elastic products by assuming $b>1$.

\subsection{Multiplicative demand}

In central channel the decision maker has to choose the proper retail price and capacity to maximize the profit. The expected channel profit is shown in equation (3.1). Following [18], we define an inventory factor $z=K / y(p)$. This transformation of variables provides an alternative interpretation of the inventory decision: if $z>\xi$, then leftovers occur; if $z<\xi$, then shortages occur. By substituting $K=z y(p)$ and $D(p, \xi)=y(p) \xi=a p^{-b} \xi$ into equation (3.1), the objective profit function can be rewritten as

$$
\pi_{c}=\left(p-c_{m}-c_{r}+g_{m}+g_{r}\right) a p^{-b}[z-\Lambda(z)]-\left(g_{m}+g_{r}\right) h-c z a p^{-b},
$$

where $\Lambda(z)=\int_{\delta_{1}}^{z}(z-x) f(x) \mathrm{d} x$. 
TABLE 2. The optimal decisions with multiplicative demand.

\begin{tabular}{lll}
\hline \hline & Central & Decentralized with no compensation \\
\hline$p \quad \frac{b\left(c_{m}+c_{r}-g_{m}-g_{r}\right)}{b-1}+\frac{b a c z_{c}^{*}}{(b-1)\left[z_{c}^{*}-\Lambda\left(z_{c}^{*}\right)\right]}$ & $\frac{b a c z_{d}^{*}}{(b-1)\left(1-\phi_{d}^{*}\right)\left[z_{d}^{*}-\Lambda\left(z_{d}^{*}\right)\right]}+\frac{b\left(c_{m}-g_{m}\right)}{(b-1)\left(1-\phi_{d}^{*}\right)}$ \\
$z$ & $\bar{F}\left(z_{c}^{*}\right)=\frac{a c(b-1)\left[z_{c}^{*}-\Lambda\left(z_{c}^{*}\right)\right]}{b a c z_{c}^{*}+\left(c_{m}+c_{r}-g_{m}-g_{r}\right)\left[z_{c}^{*}-\Lambda\left(z_{c}^{*}\right)\right]}$ & $\bar{F}\left(z_{d}^{*}\right)=\frac{a c(b-1)\left[z_{d}^{*}-\Lambda\left(z_{d}^{*}\right)\right]}{b a c z_{d}^{*}+\left(c_{m}-g_{m}\right)\left[z_{d}^{*}-\Lambda\left(z_{d}^{*}\right)\right]}$ \\
$\phi$ & - & $\frac{a c z_{d}^{*}+\left[c_{m}-g_{m}+(b-1)\left(c_{r}-g_{r}\right)\right]\left[z_{d}^{*}-\Lambda\left(z_{d}^{*}\right)\right]}{b a c z_{d}^{*}+\left[b\left(c_{m}-g_{m}\right)+(b-1)\left(c_{r}-g_{r}\right)\right]\left[z_{d}^{*}-\Lambda\left(z_{d}^{*}\right)\right]}$ \\
\hline
\end{tabular}

The above transformation of variables will help us write the optimality conditions more conveniently. Similarly with the above solution, we can rewrite the excepted profit in decentralized supply chain. The expected profit in the decentralized channel with revenue sharing is equivalent to

$$
\pi_{d}^{m}=\left[\left(1-\emptyset_{d}\right) p_{d}-c_{m}+g_{m}\right] a p_{d}^{-b}\left[z_{d}-\Lambda\left(z_{d}\right)\right]-g_{m} h-c z_{d} a p_{d}^{-b} .
$$

Below, we analyze the character of the decentralized supply chain with uncertain multiplicative demand. We follow a sequential procedure to find the optimal solution that maximizes the channel profit. The retailer decides the revenue sharing $\phi$. After observing the retailer's decision, the manufacturer decides the retail price at first and then decides the inventory factor $(z)$. The optimal decisions in both centralized and decentralized channels are presented in Table 2 . In Table $2, \bar{F}(\cdot)=1-F(\cdot)$.

Comparing the second column of Table 2 (the optimal decisions in centralized channel) with the third column of Table 2 (the optimal decisions in decentralized channel), we have the following proposition.

Proposition 6.1. In decentralized supply chain with multiplicative demand, the revenue sharing contract cannot coordinate the supply chain.

Similar to Section 4, Proposition 6.1 shows that the decentralized channel with revenue sharing cannot coordinate the supply chain. This finding suggests that the channel members had better to find some other contract which can coordinate the supply chain.

Comparing the optimal decision of inventory factor in Table 2, we have $\bar{F}\left(z_{d}^{*}\right)>\bar{F}\left(z_{c}^{*}\right)$. Notice that $\bar{F}(\cdot)=$ $1-F(\cdot)$, and thus we have the following corollary.

Corollary 6.2. With multiplicative demand, we have $z_{c}^{*}>z_{d}^{*}$.

Corollary 6.2 indicates that under multiplicative demand, the inventory factor in centralized channel is higher than that in decentralized channel. And the higher the inventory factor, the higher the capacity level. As a result, under multiplicative demand, the capacity in centralized channel is higher than that in the decentralized channel. This corollary suggests that the retailer has the motivation to help the manufacturer to establish their capacity and stimulate the manufacturer to provide a higher capacity level. Based on this, we propose a contract with capacity cost sharing.

Next, we examine whether the revenue sharing and capacity cost compensation contract can coordinate the supply chain. The excepted profit of the manufacturer in decentralized channel under multiplicative demand with capacity cost compensation can be defined as

$$
\pi_{s}^{m}=\left[\left(1-\emptyset_{s}\right) p_{d}-c_{m}+g_{m}\right] a p_{s}^{-b}\left[z_{s}-\Lambda\left(z_{s}\right)\right]-g_{m} h-c z_{s} a p_{s}^{-b} .
$$

Substituting the coordination conditions in Proposition 5.1 into equation (6.2), we find $\pi_{s}^{m}=\lambda \pi_{c}+$ $h\left[\lambda\left(g_{m}+g_{r}\right)-g_{m}\right]$ and $\pi_{s}^{r}=(1-\lambda) \pi_{c}-h\left[\lambda\left(g_{m}+g_{r}\right)-g_{m}\right]$. That means the decentralized channel with multiplicative demand can achieve coordination by using the capacity cost compensation contract we proposed. As a result, we have Proposition 6.3. 
TABLE 3 . The optimal solutions at cooperation and non-cooperation with $b=1$.

\begin{tabular}{lllllllll}
\hline \hline$p$ & $K_{c}^{*}$ & $\pi_{c}^{*}$ & $K_{d}^{*}$ & $\pi_{d}^{m *}$ & $\pi_{d}^{r *}$ & $\frac{c_{r}-g_{r}}{p}$ & $\phi_{d}^{*}$ & Effective value range of $\lambda$ \\
\hline 40 & 322.2 & 1477.8 & 251.0 & 0.2 & 1295.1 & 0.025 & 0.672 & {$[0.004,0.193]$} \\
50 & 278.3 & 1711.7 & 214.6 & 65.1 & 1459.4 & 0.02 & 0.706 & {$[0.041,0.149]$} \\
60 & 232.2 & 1747.9 & 176.0 & 109.2 & 1461.8 & 0.017 & 0.725 & {$[0.065,0.166]$} \\
70 & 184.9 & 1585.2 & 136.3 & 129.9 & 1299.9 & 0.014 & 0.733 & {$[0.085,0.182]$} \\
80 & 136.8 & 1223.2 & 96.9 & 124.4 & 977.2 & 0.013 & 0.727 & {$[0.105,0.204]$} \\
\hline
\end{tabular}

TABLE 4. The optimal solutions at cooperation and non-cooperation with $b=1.5$.

\begin{tabular}{lllllllll}
\hline \hline$p$ & $K_{c}^{*}$ & $\pi_{c}^{*}$ & $K_{d}^{*}$ & $\pi_{d}^{m *}$ & $\pi_{d}^{r *}$ & $\frac{c_{r}-g_{r}}{p}$ & $\phi_{d}^{*}$ & Effective value range of $\lambda$ \\
\hline 35 & 255.2 & 919.8 & 190.3 & 5.8 & 783.1 & 0.029 & 0.620 & {$[0.012,0.152]$} \\
40 & 222.2 & 957.8 & 162.9 & 41.3 & 789.8 & 0.025 & 0.638 & {$[0.048,0.179]$} \\
45 & 188.1 & 921.9 & 134.7 & 65.7 & 739.4 & 0.022 & 0.647 & {$[0.076,0.201]$} \\
50 & 153.3 & 811.7 & 106.4 & 78.0 & 632.7 & 0.02 & 0.648 & {$[0.100,0.218]$} \\
55 & 117.9 & 627.1 & 78.5 & 75.5 & 472.4 & 0.018 & 0.637 & {$[0.126,0.251]$} \\
60 & 82.1 & 367.9 & 52.1 & 51.7 & 265.6 & 0.017 & 0.602 & {$[0.150,0.284]$} \\
\hline
\end{tabular}

Proposition 6.3. In the decentralized supply chain with multiplicative demand, the revenue sharing and capacity cost compensation contract can coordinate the supply chain.

This proposition further demonstrates that using the revenue sharing and capacity cost compensation contract, the decentralized channel can be coordinated. In the next subsection, we discuss channel coordination with additive demand through numerical study.

\subsection{Numerical study}

A numerical example will illustrate the effects of additive demand on supply chain. We use the Stackelberg equilibrium to describe the decentralized supply chain with no capacity cost compensation. The manufacturer makes decision on the capacity level and the retailer makes decision on the revenue sharing. Assume that demand is given by $D(p, \xi)=y(p)+\xi=a-b p+\xi$, where $\xi$ is a uniformly distribution random variable defined over $[-10,10]$. Let $a=100, c_{m}=4, c_{r}=2, g_{m}=g_{r}=1, c=10$. The numerical results in Tables 3 and 4 summarize how the parameter $b$ and retail price $p$ affect the channel's decision in both centralized and decentralized supply chain. Figure 2 shows the impact of retail price $(p)$ and price coefficient $(b)$ on the optimal expected profit in centralized channel.

As illustrated in Figure 2, there has an optimal retail price to achieve maximum expect profit in the cooperation channel. Then, the decision makers need to choose a proper retail price to acquire more profit. At the same time, we can see as the parameter $b$ increases, the system's profit will decreases and the decision maker tend to cut the retail price to mitigate the negative impact on the channel's profit. This phenomenon is also illustrated in Tables 3 and 4.

We can find that there always exists a proper value range for the parameter $\lambda$, in which both the manufacturer and the retailer can acquire more profit under the revenue sharing and capacity cost compensation contract than it is under the decentralized channel. The last column of Tables 3 and 4 shows the effective range of $\lambda$ to achieve supply chain coordination. We can see that the range is not too large. However, it does not imply that the range of win-win is narrow. This is mainly because that the retailer splits most of the channel profit (note that the retailer is the leader) and the manufacturer splits a very small part of the profit. Therefore, the value of $\lambda$ cannot too high, otherwise the manufacturer's profit share is too high. Even if the value of $\lambda$ is small, by 


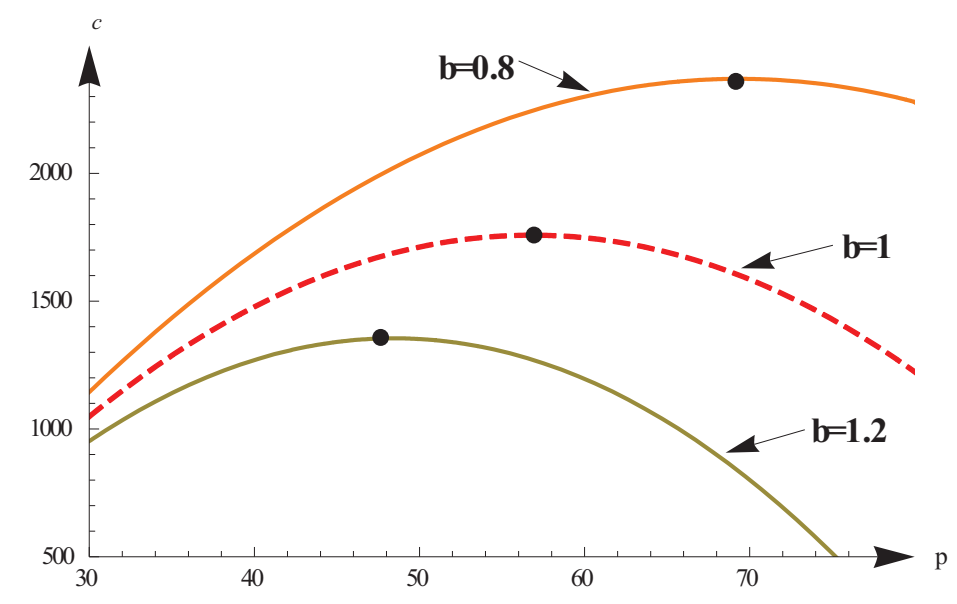

FiguRE 2. The impacts of $p, b$ on the expected profit in centralized channel.

TABLE 5. Comparison of optimal solutions between cooperation and non-cooperation.

\begin{tabular}{lllll}
\hline \hline$\xi$ & $\frac{K_{c}^{*}-K_{d}^{*}}{K_{d}^{*}}$ & $\frac{\pi_{c}^{r *}-\pi_{d}^{r *}}{\pi_{d}^{r *}}$ & $\frac{\pi_{c}^{m *}-\pi_{d}^{m *}}{\pi_{d}^{m *}}$ & $\lambda$ \\
\hline 10 & 0.323 & {$[0,0.082]$} & {$[0,1.189]$} & {$[0.034,0.105]$} \\
20 & 0.360 & {$[0,0.090]$} & {$[0,1.107]$} & {$[0.043,0.121]$} \\
30 & 0.373 & {$[0,0.094]$} & {$[0,1.087]$} & {$[0.047,0.126]$} \\
40 & 0.380 & {$[0,0.096]$} & {$[0,1.079]$} & {$[0.049,0.130]$} \\
50 & 0.384 & {$[0,0.097]$} & {$[0,1.075]$} & {$[0.050,0.132]$} \\
\hline
\end{tabular}

using the contract, both the manufacturer and the retailer can enhance their profit significantly. We will discuss this issue further in Table 5.

Both Tables 3 and 4 indicate the capacity level offered by the manufacturer tends to decrease with the increasing of retail price. This finding is intuitive because as the retailer price increases, the number of consumers who buy this product will decrease. As a result, the manufacturer will reduce his capacity level.

The result further illustrates our conclusion that the decentralized channel can be coordinated with the revenue sharing and capacity cost compensation contract. The distribution of profit between the manufacturer and the retailer depends on their bargaining power. In our channel settings, the retailer's market power is high acting as a Stackelberg leader. The numerical results also reflect that phenomenon. In Tables 3 and 4, we can find that the retailer shares most of the channel profit.

In the decentralized channel (see Sect. 4), we find that only when the retailer's revenue sharing portion $\left(\phi_{d}\right)$ satisfies $\phi_{d}=\frac{c_{r}-g_{r}}{p}$, can the decentralized channel with revenue sharing achieve coordination. However, comparing the seventh and eighth column of Tables 3 and 4 , we will find $\phi_{d}^{*} \neq \frac{c_{r}-g_{r}}{p}$. Therefore, the contract with revenue sharing cannot coordinate the supply chain.

In order to verify the effect of the contract we proposed, we also tested a lot of data and find the contract can increase the profit of both manufacturer and retailer significantly. Table 5 (where $a=50, c_{m}=c_{r}=g_{m}=g_{r}=1$, $c=3, b=1$ ) shows some of the numerical results. In Table 5 , the first column shows the parameter value of $\xi$ and the higher the parameter value, the higher the uncertainty of the demand. The second, third and fourth columns respectively show the proportion of increase in capacity, retailer profit and manufacturer profit after using the contract we proposed. We can find from the table that, by using the contract, manufacturer can obtain double or more profit and retailer can obtain an additional around $10 \%$ profit. These profit increases 
are substantial for a company. It means that either the manufacturer or the retailer has the motivation to take part in the contract and the win-win range is large. In addition, comparing the first and second columns, we find that the higher the demand uncertainty of the demand, the effective the contract is in increasing capacity investment.

\section{Conclusion}

We have illustrated that in some organic agriculture, apparels and high-tech industries, a manufacturer is very conservative in making decision on capacity. In order to enhance the profit of both the retailer and her manufacturer, the retailer has the incentive to stimulate her manufacturer to build a higher capacity. In this paper, we investigate a decentralized supply chain with stochastic demand. The channel consists of an upstream manufacturer and a downstream retailer, in which a single-period product is produced and sold in the retail market. In order to stimulate the manufacturer to provide a higher capacity, we present a revenue sharing and capacity cost compensation mechanism to constraint the behavior of both sides.

The findings of the research give us a clear picture about the decentralized channel coordination via revenue sharing and capacity cost compensation strategy between the channel members. First, we find that the optimal capacity in centralized channel is higher than that in the decentralized channel. Second, the revenue sharing contract cannot coordinate the supply chain. However, the supply chain can achieve coordination perfectly with the revenue sharing and capacity cost compensation contract. The research also provides a feasible profit distribution range, in which both the manufacturer and the retailer can acquire no less profit than that in non-cooperation. Then members can bargain over the proportion of revenue sharing and capacity cost based on their bargaining power.

Acknowledgements. Financial support from the National Key R\&D Program of China (018YFB1601401) and National Natural Science Foundation of China (71991464/71991460,71631006 and 71921001) are gratefully acknowledged.

\section{REFERENCES}

[1] G.P. Cachon, Supply chain coordination with contracts. Handb. Oper. Res. Manage. Sci. 11 (2003) 227-339.

[2] G.P. Cachon, The allocation of inventory risk in a supply chain: push, pull, and advance-purchase discount contracts. Manage. Sci. 50 (2004) 222-238.

[3] T.L. Chen, J.T. Lin and C.H. Wu, Coordinated capacity planning in two-stage thin-film-transistor liquid-crystal-display (TFTLCD) production networks. Omega 42 (2014) 141-156.

[4] J. Chod and J. Zhou, Resource flexibility and capital structure. Manage. Sci. 60 (2013) 708-729.

[5] K.S. Choi, J.G. Dai and J.S. Song, On measuring supplier performance under vendor-managed-inventory programs in capacitated supply chains. Manuf. Serv. Oper. Manage. 6 (2004) 53-72.

[6] M. Christopher, R. Lowson and H. Peck, Creating agile supply chains in the fashion industry. Int. J. Retail Distrib. Manage. 32 (2004) 367-376.

[7] Y. Dong and K. Xu, A supply chain model of vendor managed inventory. Transp. Res. Part E: Logistics Transp. Rev. 38 (2002) 75-95.

[8] G.D. Eppen and A.V. Iyer, Backup agreements in fashion buying - the value of upstream flexibility. Manage. Sci. 43 (1997) $1469-1484$.

[9] M. Erkoc and S.D. Wu, Managing high-tech capacity expansion via reservation contracts. Prod. Oper. Manage. 14 (2005) $232-251$.

[10] X. Gan, S.P. Sethi and H. Yan, Coordination of supply chains with risk-averse agents. Prod. Oper. Manage. 13 (2004) $135-149$.

[11] M. Goyal and S. Netessine, Strategic technology choice and capacity investment under demand uncertainty. Manage. Sci. 53 (2007) 192-207.

[12] S. Jahanbin, P. Goodwin and S. Meeran, New product sales forecasting in the mobile phone industry: an evaluation of current methods. Int. Inst. Forecasters (2013).

[13] Y. Jin, S. Wang and Q. Hu, Contract type and decision right of sales promotion in supply chain management with a capital constrained retailer. Eur. J. Oper. Res. 240 (2015) 415-424.

[14] L. Kaye, H\&M, The World's Largest Organic Cotton User_Better Enough? Available from: https://www.triplepundit.com/ 2014/08/hm-organic-cotton/ (2014).

[15] M.A. Lariviere, Supply chain contracting and coordination with stochastic demand. In: Quantitative Models for Supply Chain Management. Kluwer Boston (1999). 
[16] S. Li, Z. Zhu and L. Huang, Supply chain coordination and decision making under consignment contract with revenue sharing. Int. J. Prod. Econ. 120 (2009) 88-99.

[17] S. Oh and Ö. Özer, Mechanism design for capacity planning under dynamic evolutions of asymmetric demand forecasts. Manage. Sci. 59 (2013) 987-1007.

[18] N.C. Petruzzi and M. Dada, Pricing and the newsvendor problem: a review with extensions. Oper. Res. 47 (1999) $183-194$.

[19] M. Piedrahita, Global Component Shortage: Why it's Happening and How You Can Protect Your Production Schedules. Available from: https://www.219design.com/global-component-shortage/ (2018).

[20] E.L. Plambeck and T.A. Taylor, Implications of renegotiation for optimal contract flexibility and investment. Manage. Sci. 53 (2007) 1872-1886.

[21] G. Roels and C.S. Tang, Win-win capacity allocation contracts in coproduction and codistribution alliances. Manage. Sci. 63 (2016) 861-881.

[22] R. Swinney, G.P. Cachon and S. Netessine, Capacity investment timing by start-ups and established firms in new markets. Manage. Sci. 57 (2011) 763-777.

[23] T.A. Taylor, Supply chain coordination under channel rebates with sales effort effects. Manage. Sci. 48 (2002) $992-1007$.

[24] T.A. Taylor and E.L. Plambeck, Supply chain relationships and contracts: the impact of repeated interaction on capacity investment and procurement. Manage. Sci. 53 (2007) 1577-1593.

[25] Y. Wang, L. Jiang and Z.J. Shen, Channel performance under consignment contract with revenue sharing. Manage. Sci. 50 (2004) 34-47.

[26] W.K. Wong, J. Qi and S.Y.S. Leung, Coordinating supply chains with sales rebate contracts and vendor-managed inventory. Int. J. Prod. Econ. 120 (2009) 151-161.

[27] J. Wu and X. Chao, Optimal control of a Brownian production/inventory system with average cost criterion. Math. Oper. Res. 39 (2014) 163-189.

[28] W. Xie, Z. Jiang, Y. Zhao and J. Hong, Capacity planning and allocation with multi-channel distribution. Int. J. Prod. Econ. 147 (2014) 108-116. 